\title{
The Role of Higher Education Evaluation System in the Senior Human Resources Development
}

\author{
A novelty of developing during evaluating
}

\author{
Feiye Zhang \\ College of Information System and Management \\ National University of Defense Technology \\ Changsha, Hunan, P.R.China \\ e-mail:zhangfeiye@126.com
}

\author{
Shenghao Guo \\ School of Government, Peking University \\ Center for Human Resource Development and Management \\ Research of Peking University \\ Beijing, P.R.China \\ e-mail: shenghao_guo@sina.com
}

\begin{abstract}
Higher education is the main method of senior human resources development (HRD) and its potential role need mining urgently. The paper presents a novelty that regarding evaluation of higher education as the method of HRD, validated its feasibility, analyzed the value and expounded the practice. In view of the higher education evaluation, its potential value of higher education and HRD need exploring, regarded as an important method of constructing a powerful nation of human resources.
\end{abstract}

Keywords-higher education; evaluation of higher education; human resources development

\section{INTRODUCTION}

Human capital accumulation precedes the economic and social development, and the promotion of quantity and quality of human resources determines a nation's trajectory of development. At present, constructing a powerful nation of human resources has become the common goal of all countries. China is in a critical period of economic and social structural adjustment and transformation. The problem of senior human resources shortage is particularly prominent, it is quite important to focus on connotative development of higher education and promote the quality of human resources. Teaching, scientific research and social service are the three major functions of modern universities. Higher education is not only the means of production for human resources but also the approach to raising the quality of human resources. Higher education has played a vital role in cultivating and supplying a large number of highquality talents to society.

\section{THE PROBLEMS IN CURRENT HIGHER EDUCATION EVALUATION AND SENIOR HUMAN RESOURCES DEVELOPMENT}

\section{A. Status ambiguity in higher education evaluation}

China's higher education took off early, but developed relatively slow, evolved successively from goal-oriented evaluation mode in the mid $80 \mathrm{~s}$ to multiple target higher education evaluation in the $90 \mathrm{~s}$ and meta-evaluation system early 21 st. Current researches mainly focus on the teaching reform of higher education, such as personnel training mode, curriculum setting and teaching methods of research, there is not too much in-depth study on the function of higher education evaluation should have worked proper and maximized. This is mainly embodied in that subject and object of higher education evaluation is unclear and the evaluation system research is not thorough, especially the deep-seated effects of higher education evaluation are yet to be explored.

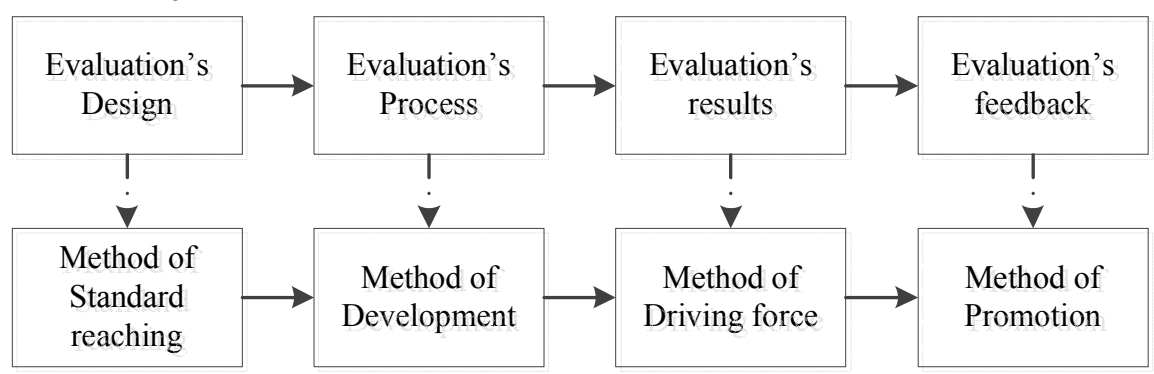

Figure The practice of the system of higher education evaluation in HRD 


\section{B. Imperfections of higher education evaluation system}

Some scholars believe that china's higher education evaluation is in a stage of collecting, describing and recommending valuable information for decision-makers. For example, it's severe for the lack of humanistic characteristic. Compared with modern western countries, we are still in a backward position. Nowadays though efforts have been made in trying to applying quantitative methods and content coordination to higher education evaluation, it has failed to realize the evaluation of subject and object scientifically and systematically. Especially from results orientation, the effect of the higher education has failed to be evaluated effectively. China's higher education evaluation system has been adversely affected by the problems of too much administrative interference, lower scientificity and weak initiative of evaluated objects, etc. The evaluation system is often above the purpose of assessment and the subject of education cannot be fully evaluated. The basic role of evaluation as a means of evaluation is not able to show up, and it is harder to bring the deep-seated role of human resources development into play.

\section{The lack of effective development methods for senior human resources}

Colleges and universities are the main positions for developing senior human resources. But currently, universities tend to develop human resources through traditional teaching methods. In today's society of diversified knowledge and individualized talent, such traditional methods are difficult to adapt. Higher education institutions often pin their hopes on high-quality teachers for nurturing talent. They hope to promote their own disciplines and strengthen scientific research through the introduction of talent, so as to drive the development of human resources. In fact, high-quality teachers are rare and the high quality teachers are not equal to high quality teaching. Likewise, high quality teaching does not equal high quality teaching achievements. From the perspective of state demands, universities should cultivate senior talent and human resources, but the current approaches to the HRD in universities are obviously not effective enough.

\section{THE FEASIBILITY REGARDING EVALUATION OF HIGHER EDUCATION AS THE METHOD OF HRD}

\section{A. regarding evaluation system as the method of HRD}

Evaluation system originated from performance appraisal. Evaluation system is the criterion and basis for judging results. With the development of the concept of performance management and maturing of HRD technology, evaluation has become a way of development gradually. The ultimate goal for the establishment of evaluation system is improving the comprehensive strength of the organization and providing high-quality talent for the respective areas. Evaluation system can realize the goal of human resources development. Human beings themselves while as a kind of capital also did not lose their initiative, No matter what role playing in organization evaluation system, External evaluation can be instantly transformed into its own power by internal psychological mechanisms, providing new reference for strategy improving and appropriate strategies to further develop themselves. By evaluation, firstly the standard of goals can be established in purpose of definitely pinpoint the extent of amount or degree. Secondly, the evaluation system can make object aware of the gap with the target in the process of evaluation about the behavior or ability level currently, to strengthen the understanding of correct behavior or level and improve the introspection. Then Evaluation results can be used as the basis for assessment, understanding of basic situation currently, and motivate behavior by rewarding and punishments .lastly, giving feedback for evaluation process and results, make a targeted tutoring, strengthen introspection induction along with external corrective improved simultaneous, so as to realize the external and self-development will be achieved.

\section{B. The particularity of higher education and the applicability of the evaluation development}

Although differences existed between higher education and other organizations on the factors of HRD such as content, the key is the object of higher education. Because of difference of object, the development methods should be adjusted according to the conditions of the real object and the relevant environment. On the one hand, students in university have higher level of knowledge reserve but relatively less experience, so the technicality and theorizing are more obvious On the other hand, value and significance of development are quite distinct on account of talent plasticity. Although difference existed in development objects, however, in view of the purpose of evaluation as well as perspective of human resource development, regarding assessment as a tool of development is common in the level of methodology, it should be noted that adapting and adjusting according to the characteristic of higher education. It's reasonable to equate higher education with the process of HRD; higher education is the main method of senior HRD; from the perspective of educational evaluation, higher educational evaluation has always existed in higher education, but still in the initial stages of development, the same with the traditional HRD in the process of evaluation of the early stage of the development, the nowadays evaluation is advancing towards the method of development and got consensus overseas. It could draw on the experience of the evaluation theory in HRD, and further develop as an important method of HRD. 


\section{THE VALUE AND PRACTICE OF THE SYSTEM OF HIGHER EDUCATION EVALUATION IN HRD}

\section{A. Evaluation's design as a method of reaching standard}

Evaluation system must fully grasp the key indicators of evaluation objects. The purpose of designing higher education evaluation is pinpointing the goals of higher education that need to be achieved and the weighting of each indicator. A clear goal is the premise for education and HRD to keep orientation and achieve goals. With the economical and social transformation, state demand for senior talent changes, and the orientation for cultivating talent in higher education and standard of weighing indicators also change. In designing an evaluation system for curriculum setting and senior talent cultivating modes, firstly, owning strategic consciousness in purpose of implementing talent strategy gradually according to evaluation indicators. Secondly, keeping consciousness of target-oriented, evaluation should remedy the situation of ignorance about humanistic characteristics currently in higher education evaluation, and indicators should be humanisticoriented, emphasis on judging of the potentials tapping, that is, we should take into consideration the orientation of talent cultivation, weighting of indicators for reaching the standards in a coordinated manner, then fully integrate them into HRD. Lastly, design of evaluation should concentrate on operationalization and materialization. Whether the practicality and directivity of evaluation could be influenced by indicator itself obviously, the only path to operational is materialization. For example, behaviorally anchored rating scales would be available for the qualitative and fuzzy indicators.

\section{B. process of evaluation as the method of development}

The evaluation process itself is the process of tutoring and development. In the process of evaluation, teachers, students and teaching superintendents recognize the factors that assessors value most, that is, through the evaluation process, those practicing education will have a better understanding of the policies of the state and educational departments for senior talent cultivation. In the process of evaluation, those practicing education, as participants from the beginning to the end, can realize what the criteria are and the gap between their current status and the standards. This process based on actual perception of the gap or difference between realities and requirements, urging those being developed to have a profound and the actual perception of evaluation standard level, and guiding those being evaluated to learn correct behavior then introspection of their behavior. The evaluation process for the purpose of development, it requires pinpointing the criteria along with feedback while doing higher education evaluation, so that those being evaluated will understand the education goals and concrete on-site criteria and are briefed on the excellent experience in process such as how other excellent people and organizations handle the problem. Those conducting the evaluation must remember that evaluation itself is development, while those being evaluated must keep in mind that the process of being evaluated is itself a good opportunity for goal clarification and self-improvement.

\section{Evaluation results as assessment methods}

Making evaluation results as assessment methods is the most traditional use for higher education evaluation. Firstly, those evaluating higher education can be familiarized with the current basic circumstances and development levels of higher education and recognize the main achievements and deficiencies. This plays the role as an investigation of the higher education evaluation. Based on the research for situation currently, as a result, those conducting the evaluation can make plans for further cultivating higher education talent and improving the management of higher education. Secondly, on the basis of assessment results, they can award, warn or punish those being evaluated. Teachers, students and education administrators are usually extremely sensitive to the citations and punishments resulting from the evaluation. They will make corresponding consolidations and digest the results that play the role of a clear guidance.

\section{Evaluation feedback as the basis for promotion}

Evaluation feedback is a key in evaluation system for the purpose of development. The purpose of evaluation is to raise the level of higher education instead of being stuck in citations and punishments based on evaluation results. Although in the process of evaluation, those being developed form the perception to critical criterion and induce the self-reflection, as to rewards and punishment from evaluation results, are those being developed reinforcement or fade in behavior, in order to play the function of the development, it's necessary to find problems during the evaluation process and results then giving corresponding feedback and mentoring. The current higher education evaluation has evolved from attention to the needs of those conducting evaluations to the quality development of those being evaluated. In addition to the subjective initiative of those being evaluated, quality development entails outside assistance and guidance as well. This makes higher demands on those conducting evaluations or higher education administrators. All this makes timely communication, feedback and tutoring particularly important. Firstly, feedback must be timely. In addition to the feedback during the evaluation process, the evaluation result feedback should also be concise as much as possible and serves as a stimulant while those being evaluated are aware of their problems. Secondly, feedback should be tutoring on the basis of communication, with the focus on exchange of opinions rather than admonishments, achieving a plan for promotion through an insight and analyzing into the problems. Thirdly, intentionality of feedback is necessary, feedback should help those being evaluated recognize the goals of talent cultivation, the cultivation modes for the current stage, the disparity in level and an in-depth analysis of its reasons, deviate is negative from higher 
education, the purpose of senior human resources development in process of feedback need keep in mind. At last, further formulation of a revised plan is needed to improve its feasibility, such as listing the schedule for promotion and the level expected to be achieved. In this way, the level of higher education and senior human resources is expected to be raised in a down-to-earth and effective manner, based on disparity in facts and the current conditions and by aiming at actual problems.

\section{CONCLUSION}

In the innovation of performance management idea and drive by mature technology of human resources development, the value of developing evaluation system get increasingly attention from academic and practice. Human resource is significant and higher education is the crucial method of senior human resources development. Higher education evaluation as an important part of higher education, also has a great value of human resources development, By discovering and using the potential value of the higher education evaluation system, regarding Higher education evaluation as a method of human resources development can provide strategy for current higher education and senior human resources development. By higher education evaluation system, Education stakeholders can be convinced of the goal and direction of higher education, giving guidance in the process of evaluation, regarding evaluation results as the assessment basis for incentives, finally according to the evaluation to understand present situation and level of education, analyzing the gap for feedback. With economical and social transformation, china is in urgent need of senior human resources, higher education is the main method of senior human resources development, and higher education evaluation will play a vital role.

\section{REFERENCES}

[1] Ulrich D, Brockbank W, Yeung A K, et al. Human resource competencies: An empirical assessment[J]. Human Resource Management, 1995, 34(4): 473-495.

[2] Werner J, DeSimone R. Human resource development[M]. Cengage Learning, 2011.

[3] Arreola R A. Developing a comprehensive faculty evaluation system: A handbook for college faculty and administrators on designing and operating a comprehensive faculty evaluation system[M]. Anker Publishing Company, Inc., 176 Ballville Road, PO Box 249, Bolton, MA 01740-0249, 2000

[4] Clark B R. The higher education system: Academic organization in cross-national perspective[M]. Univ of California Press, 1986.

[5] Astin A W. Assessment for excellence: The philosophy and practice of assessment and evaluation in higher education[M]. Rowman \& Littlefield Publishers, 2012.

[6] .Rauch A, Frese M, Utsch A. Effects of Human Capital and Long Term Human Resources Development and Utilization on Employment Growth of Small - Scale Businesses: A Causal Analysis1[J]. Entrepreneurship Theory and Practice, 2005, 29(6): 681-698.
[7] Shujing Y, Chaoming L. Human Capital Accumulation and Regional Total Factor Productivity [J][J]. Economic Research Journal, 2006, 4: 90-96.

[8] Wang Y, Yao Y. Sources of China's economic growth 1952-1999: incorporating human capital accumulation[J]. China Economic Review, 2003, 14(1): 32-52.

[9] Delahaye B L. Human resource development[J]. Brisbane: John Wiley \& Son Australia, Ltd, 2000.

[10] Astin A W. Assessment for excellence: The philosophy and practice of assessment and evaluation in higher education[M]. Rowman \& Littlefield Publishers, 2012

[11] Brown G A, Bull J, Pendlebury M. Assessing student learning in higher education[M]. Routledge, 2013.

[12] Hazelkorn E. Rankings and the Reshaping of Higher Education: the Battle for World Wide Excellence[J]. 2011.

[13] Katsikeas C S, Leonidou L C, Morgan N A. Firm-level export performance assessment: review, evaluation, and development[J]. Journal of the Academy of Marketing Science, 2000, 28(4): 493-511. 